\title{
Auge y crisis del Partido Socialista pampeano y su rol en la organización del movimiento agrario (1913-1921)
}

\author{
Federico Martocci
}

IESH, UNLPam

fedmartocci@hotmail.com

\section{Introducción}

En la edición conmemorativa del primero de mayo, el órgano de prensa del Centro Socialista de Santa Rosa (capital del Territorio Nacional de La Pampa), cuyo título era Germinal, ${ }^{1}$ repasaba en 1920 su desempeño en materia política, cooperativa, cultural y gremial. Sobre este último punto, los socialistas señalaban:

Siendo nuestro Territorio, esencialmente agrícola-ganadero, la acción gremial socialista se ha dirigido con preferencia a la organización de los trabajadores del campo. [...] El gran movimiento agrario de 1912, terminado con la conquista de importantes mejoras para los trabajadores del campo, fué iniciado por socialistas. Entre ellos merece mencionarse al ciudadano Antonio Buira afiliado a nuestro Centro y ex-Secretario General de la Liga Agraria de La Pampa y principal organizador del movimiento. [...] Reorganizada precipitadamente la Liga Agraria en 1919 los chacareros se lanzaron en el mismo año a una nueva huelga. La brutal represión del gobierno radical sofocó el movimiento mandando a la cárcel a los más activos e inteligente[s] chacareros. Entre ellos a nuestros compañeros Antonio Buira y Luis Glerean. [...] Con el fracaso de este movimiento terminado con solo algunas ligeras ventajas obtenidas por algunas colonias, la organización de los agrarios decayó.

1. Este periódico se fundó en 1914 y en 1925 se convirtió en el órgano de prensa de la Federación Socialista Pampeana, creada ese mismo año. Desde 1919 se publicó con una frecuencia semanal y en 1927 pasó a ser diario, editado siempre en la ciudad de Santa Rosa.

(Archivos, año VI, $\mathrm{n}^{\circ}$ 12, marzo de 2018, pp. 143-163) 
Pero no ha muerto. La situación insegura del chacarero, la constante obra de educación ejercida por el socialismo ha hecho revivir en los agrarios la necesidad de unirse para poder subsistir y triunfar. ${ }^{2}$

De inmediato agregaban que el movimiento gremial carecía de "consistencia” en Santa Rosa, la ciudad más importante del Territorio, razón por la cual habian intentado organizar a los panaderos y tipógrafos aunque sin "mayores resultados". Por tal motivo, a siete años de la creación de dicho Centro, el primero del Partido Socialista (PS) en la zona, ellos reconocian que en lo referido a la organización de los trabajadores los logros principales hasta entonces se habían alcanzado en el campo y mediante el accionar de los propios "agrarios", entre ellos Antonio Buira y Luis Glerean. Pero estos eran solo dos de los muchos que integraban las filas socialistas, como demostraremos aquí. Vale plantear entonces un argumento que estructura la pesquisa: para decirlo sintéticamente, la tesis sobre el fracaso del proyecto que el PS esbozó para el agro a comienzos del siglo XX constituye más bien un obstáculo para avanzar en el análisis de la expansión de esa cultura de izquierda en el interior argentino. ${ }^{3} \mathrm{El}$ propósito de este artículo es analizar el despliegue de esa fuerza politica en una región rural teniendo en cuenta la gravitación que tuvieron en el PS los habitantes del agro.

Sin desconocer las limitaciones que experimentó el socialismo para llevar su propaganda al medio rural, hecho que daria cuenta de la escasa incidencia de esa fuerza política en el agro (Barandiarán, 2010), aquí procuramos retomar esa discusión, brindar nuevas evidencias y complejizar ciertas interpretaciones. A modo de hipótesis, podemos adelantar que durante su etapa inicial la dirigencia del PS en el Territorio pampeano tuvo un carácter mucho más plebeyo que el de la elite parlamentaria nacional del socialismo (a quienes identificaban con sectores universitarios) y que en sus filas existía una nutrida cantidad de agricultores. Si bien algunos leian La Vanguardia y participaban de las luchas agrarias antes de la creación del PS en la región, con la expansión del partido en esa zona del interior argentino la relevancia que adquirieron fue más notoria y bregaron por la organización de las masas rurales. La activa militancia gremial de algunos, en particular de Antonio Buira (el referente más importante), los llevó a cuestionar el desempeño partidario en el plano politico, a desestimar importantes propuestas de la dirigencia socialista nacional y a abandonar las filas

2. Germinal, 29 de abril de 1920, $\mathrm{n}^{\circ}$ 194, Santa Rosa.

3. En relación con dicha tesis, véase Adelman (1989). 
del PS junto con otros "terceristas" luego del IV Congreso Extraordinario de 1921, llevado a cabo en Bahía Blanca.

Otros investigadores demostraron la participación de los socialistas en la huelga agraria de 1919 (Asquini, 1999; Valencia, 2008b), así como en diversas instancias de organización de los trabajadores en las ciudades más pobladas (Valencia, 2008a). Sin embargo, ninguno se concentró en la enorme difusión que tuvo el PS en las zonas rurales, ya sea a partir de la presencia de militantes, de la distribución de periódicos y otras publicaciones o de la organización de pequeñas bibliotecas en las que se realizaban diversas actividades de carácter cultural. En trabajos anteriores dimos cuenta de las acciones socialistas en materia cultural (Martocci, 2015), pero aquí focalizaremos en la organización del movimiento agrario en el período que va de 1913 a 1921, es decir, entre la creación del PS en el Territorio pampeano y la desarticulación de la Liga Agraria a raíz de la represión estatal. Como se podrá advertir, no era casual que muchos integrantes de dicha Liga se identificaran con el socialismo y que el PS, como se ve en la cita inicial, se arrogara la organización de los "trabajadores del campo" en la década del diez e hiciera mención de dos agricultores del partido: Buira y Glerean. Pero estos no eran los únicos: Emilio Ottone integraba con ellos el Centro Socialista santarroseño y había otros desperdigados por las zonas rurales, entre ellos Demetrio Buira, Emilio Carnicelli, Florentino Ghiribaldi, Blas Nievas y Eliseo Tarquini. Excepto Demetrio (hermano de Antonio), que era un pequeño propietario, los otros hasta donde sabemos arrendaban tierras en diferentes colonias agrícolas de la región. Por ello, conocian de primera mano la problemática agraria, eje central de los tópicos que el PS colocaba en el debate público nacional.

Aquí veremos que muchos de los líderes agrarios del Territorio abrevaban en el socialismo, que concebían como un logro resonante la organización de la Liga Agraria y, especialmente, que no acataban de manera acrítica el proceder y las posturas de la dirigencia nacional. Por el contrario, en ocasiones analizaron con gran autonomía la realidad partidaria y tomaron como base sus propias experiencias para discutir temas delicados, por ejemplo la conflictiva relación entre el PS y el movimiento obrero, cuestión que ha sido visitada por los historiadores. ${ }^{4}$ La concepción de Juan B. Justo al respecto establecía que la lucha política y la sindical debian fluir por sendas paralelas pero separadas, posición que imprimió a ese vínculo un carácter esquivo. Si bien dicha postura se consolidó en el XIV Congreso Ordinario de 1918 (Camarero, 2005: 188-189; Herrera, 2007: 30-31), ello no obturó la emergencia de

4. Véase Tortti (1989), Camarero y Schneider (1991), Camarero (2005 y 2015), Martínez Mazzola (2011) y Ceruso (2015 y 2017). 
críticas contra la estrategia reformista. La creación en 1914 del Comité de Propaganda Gremial (CPG), cuyo principal dirigente era José Penelón, constituía un antecedente porque entre las preocupaciones de sus impulsores estaba la dispersión de los trabajadores del PS (Camarero, 2015: 165-169).

Sin considerar detenidamente las posturas del socialismo local ante la problemática gremial es dificil explicar la ascendencia que alcanzaron estos agricultores en el ámbito rural. Ese desconocimiento llevó a otros autores a exaltar en demasia la presencia anarquista en el agro y desestimar por completo el papel del PS (Doeswijk, 2014: 124-142) o a postular que los socialistas se inclinaban en bloque a la actividad política y dejaban de lado la vinculación con los trabajadores (Folco, 2014: 124). Aquí rebatiremos estas posturas mediante la exploración de libros y folletos publicados por La Vanguardia, cartas y notas de agricultores, el expediente judicial realizado por la detención de socialistas en la huelga agraria de 1919 y la prensa partidaria (especialmente Germinal). Reconstruiremos así el rol del PS en la organización del movimiento agrario, las criticas de algunos líderes al accionar socialista en el plano político y las consecuencias que ello tuvo a inicios de la década del 20, a saber, la retracción de la lucha agraria y la pérdida de afiliados experimentada por el PS.

\section{Consideraciones sobre el socialismo pampeano en sus primeros años}

En 1913 se creó en el Territorio el PS y su primer Centro fue el de Santa Rosa. Uno de sus impulsores fue Pedro E. Pico, abogado y dramaturgo nacido en Buenos Aires que entre 1912 y 1918 se radicó en Santa Rosa, puso un estudio jurídico y militó a favor de la organización agraria, de reformar los contratos de arrendamiento y del cooperativismo. Pico acompañó en 1913 a los flamantes diputados nacionales del PS Juan B. Justo y Nicolás Repetto en la gira que realizaron por el Territorio. En esa gira los diputados visitaron campos de la región y es probable que conocieran a algunos de los principales referentes de la Liga Agraria. En un alto que hicieron luego de recorrer campos en el norte pampeano, estuvieron en la chacra de Luis Denegri, activo agricultor georgista ya en esa época que, posteriormente, presidió la Liga (Armani, 2006: 151). Quizá también en esa ocasión conocieron a Buira, quien en 1912 fue uno de los artífices de la organización de la Liga Agraria en la colonia Inés y Carlota, entidad de la que fue secretario general.

¿Era casual que Justo y Repetto visitaran la región y recalaran en los campos? A todas luces no lo era, debido, por un lado, a que la cuestión agraria era un tema central para el PS desde los albores del siglo XX 
(Graciano, 2006) e incluso el programa para el campo (1901) se inscribía en un proceso de expansión partidaria hacia el interior que contemplaba problemas vitales para una nutrida población rural (Poy, 2016) y, por otro, a que los agricultores pampeanos en muchos casos se identificaban con el socialismo. Un ejemplo es el de Eliseo Tarquini, que ya entre 1908 y 1910 leía y solía escribir notas en La Vanguardia (Adelman, 1989: 329-330). Esta evidencia, que amerita un abordaje aparte, da cuenta de que algunos agricultores leían el principal diario socialista antes de la emergencia del PS en esas latitudes. Tarquini fue también un líder agrario y un colaborador de Germinal, periódico que desde sus primeros años analizó temas vinculados con el agro. Por ejemplo, criticaban la desunión de los agricultores, y lo hacian a partir de un diálogo titulado "La Crisis y el Labriego": alli este último le preguntaba a la primera por qué se empeñaba en habitar sus campos, siendo que en las ciudades tenía un próspero ámbito de acción; la Crisis le respondía que no se iría porque los labriegos, pese a ser más fuertes que los hombres "de ciudad", carecian del valor y la capacidad para utilizar la fuerza con el objetivo de expulsarla. ${ }^{5}$

En 1914 el Territorio contaba con una población de 101.338 habitantes, cifra que hacia 1920 trepó a 122.535 . Las ciudades más pobladas eran Santa Rosa y General Pico, que a inicios de los años 20 tenían 5.563 y 6.449 habitantes, respectivamente. En las otras localidades los habitantes no alcanzaban siquiera los 3.000, excepto en Intendente Alvear y General Acha que estaban cerca de ese guarismo (Di Liscia y Lluch, 2014: 104-105). Para 1914, la población total del Territorio se dividia en 47.387 habitantes urbanos y 53.591 rurales, cifra esta última que en 1920 bajó a 49.421 (Censo General del Territorio Nacional de la Pampa, 1942: 16). En un espacio con estas características, cuya economía se basaba en la producción primaria y carecía de industrias importantes, la mayoria de las explotaciones dedicadas a la agricultura, la actividad económica más importante, se encontraban bajo arrendamiento (más del 70\%). En ese marco, se explica que el PS ejerciera influencia entre los productores y que la conformación partidaria presentara diferencias respecto de la que tenía el socialismo en Buenos Aires u otras ciudades populosas del país. Detengámonos un momento en el carácter plebeyo del PS pampeano.

Para 1914 el PS santarroseño tenía unos cincuenta afiliados, de los cuales veinte asistían a las asambleas mensuales. Sin embargo, los buenos resultados electorales entre 1914 y 1915 dieron lugar a la fundación de nuevos centros en General Pico (1916), Eduardo Castex (1918) y Realicó (1919) (Valencia, 2008a: 55-69). Esta expansión para

5. Germinal, $\mathrm{n}^{\circ}$ 11, 6 de septiembre de 1915, Santa Rosa. 
Germinal representaba "el despertar de conciencia proletaria". ${ }^{6}$ Ese periódico no solo circulaba en las localidades, sino además en las zonas rurales. En muchos casos sus agentes eran agricultores, como sucedía en Anguil, Alpachiri y Eduardo Castex con Alonso Blanco, Nicolás Lazarte y Juan Bottino, respectivamente. ${ }^{7}$ Emilio Carnicelli era agente en colonia La Gloria y Antonio Tarquini, el hermano de Eliseo, en colonia Inés y Carlota. ${ }^{8}$ Las colonias agrícolas eran espacios donde se leía Germinal.

Los agricultores no se limitaban a la lectura de la prensa, ya que además participaban en las actividades del PS. Antonio Buira fue uno de los oradores en el acto organizado antes de las elecciones de 1914, y lo hizo junto a los candidatos Pedro E. Pico y Amelio Spongia Friderich. ${ }^{9} \mathrm{El} 1$ de mayo de 1916 también fue Buira el que habló en la plaza capitalina sobre la significación de esa fecha ${ }^{10} \mathrm{y}$, además, representó al Centro Socialista de Santa Rosa en el II Congreso Extraordinario del PS, llevado a cabo en Buenos Aires durante julio de 1915. También fue delegado del Centro en el XIII Congreso Ordinario del PS (1916), en el III Congreso Extraordinario del PS (1917) y en el IV Congreso Extraordinario del PS (1921), situación que denota su relevancia en las filas socialistas.

Nacido en 1884 en Marsella, Francia, mientras sus padres viajaban desde España a América, Buira vivió en las provincias de Santa Fe y Córdoba antes de recalar con su familia en el Territorio. Cuando se incorporó al Centro santarroseño ya era un referente agrario y tenía una nutrida experiencia en el ámbito gremial: por ello, como veremos, reconocía que llegó al PS a partir de su accionar en ese ámbito. Cabe advertir que Buira tuvo esa significación en un marco particular: la dirigencia del PS estaba integrada por Pico (abogado), Spongia Friderich (agente judicial), Hugo Nale (constructor de obras), Domingo Gentili (autodidacta), Antonio Nale (sastre), Nicolás Pracilio (gomero), Víctor Lordi (mecánico), Lázaro Galdín (peluquero), Juan Pagés (peluquero), Simón Elizondo (librero), Emilio Ottone (agricultor), Demetrio Buira (agricultor), Luis Glerean (agricultor), Arturo García (comerciante) y Pedro Olivieri (comerciante), entre otros. ${ }^{11}$ Hugo Nale fue a su vez su secretario general y uno de los directores de Germinal. Buira no era el único agricultor que integró la dirigencia, pero sin duda fue el más

\footnotetext{
6. Germinal, $\mathrm{n}^{\circ} 153,10$ de julio de 1919, Santa Rosa.

7. Germinal, $\mathrm{n}^{\circ}$ 156, 31 de julio de 1919, $\mathrm{y} \mathrm{n}^{\circ}$ 160, 28 de agosto de 1919, Santa Rosa.

8. Germinal, $\mathrm{n}^{\circ} 166,9$ de octubre de 1919, Santa Rosa.

9. Germinal, $\mathrm{n}^{\circ}$ 2, 12 de septiembre de 1914, Santa Rosa.

10. Germinal, $\mathrm{n}^{\circ}$ 30, 1 de mayo de 1916, Santa Rosa.

11. En todos los casos, integraron en diferentes épocas la Comisión Administrativa del Centro capitalino.
} 
importante. Al promediar 1916 presidia las reuniones de la Comisión Administrativa y ese mismo año fue candidato junto a Hugo Nale para ocupar una banca en el Concejo Municipal de Santa Rosa, pero no accedió porque perdieron las elecciones. ${ }^{12}$ En marzo de 1920 otra vez se postuló, junto a Pico, Nale y Glerean, aunque fueron nuevamente derrotados. ${ }^{13}$ Como puede advertirse, la dirigencia local del PS estaba integrada por hombres con ocupaciones disímiles y que, salvo excepciones, no tenían estudios universitarios, a diferencia de aquellos que monopolizaban la representación parlamentaria socialista.

Un conjunto de agricultores adquirió durante los primeros años del socialismo pampeano una relevancia notoria. Como se verá en el próximo apartado, desde ese lugar procuraron la organización de las masas rurales, especialmente de los arrendatarios, y lideraron una de las más importantes huelgas agrarias de la región. Sin embargo, algunos abandonaron el PS luego de que la represión estatal sofocara esa huelga, en un contexto de serios conflictos hacia el interior del socialismo argentino. Ciertas diferencias, no obstante, se podian ver claramente desde hacia varios años. La postura del PS (en especial de Justo) sobre el lugar y la función de la actividad política y la gremial dio lugar a un permanente debate interno, que se remontaba a la década inicial del siglo XX, cuando el grupo que luego integró el sindicalismo planteó por primera vez el tema y se escindió del PS (Camarero, 2015: 162-164). ${ }^{14}$

La dirigencia del PS santarroseño no fue ajena a ese debate. En el II Congreso Extraordinario, luego de una intervención del delegado Amadeo Argibay en la que planteó la influencia "completamente nula" del PS en el movimiento obrero, ${ }^{15}$ Buira pidió la palabra. Alli afirmó que los socialistas pampeanos, sin descuidar la intervención política, se habían dedicado a "la acción puramente gremial". Por eso, reclamaba que "se diera preferente atención a la organización gremial de los trabajadores" en el Congreso. Luego de las intervenciones de otros delegados, Buira agregó que la influencia que tenía "en otra época" el PS dentro de la organización gremial había sido reemplazada por "una grandísima actividad política y electoral". Por ello, lamentaba el "aislamiento" en que vivian muchos socialistas que estaban "encerrados" en los Centros y "descuidando por completo la acción dentro del movimiento gremial". Y al concluir, señalaba que, si bien no le restaba importancia a la acción política, él había llegado al PS "por medio de la asociación gremial”, razón

12. Germinal, $\mathrm{n}^{\circ}$ 42, 1 de noviembre de 1916, Santa Rosa.

13. Germinal, $\mathrm{n}^{\circ} 189,18$ de marzo de 1920, Santa Rosa.

14. En relación con las críticas del sindicalismo al parlamentarismo, ver Belkin (2013).

15. Partido Socialista, Versión taquigráfica del II Congreso Extraordinario (XIV Congreso Nacional), Buenos Aires, Talleres Gráficos de L.J. Rosso y Cía., 2015, p. 172. 
por la cual creía que era alli donde se formaba "la verdadera conciencia politica de los trabajadores", palabras que fueron muy aplaudidas. ${ }^{16}$

Antonio Buira escuchó personalmente además las discusiones en el III Congreso Extraordinario del PS, donde el grupo parlamentario del Comité Ejecutivo (de tendencia aliadófila) fue derrotado por la minoría, entre ellos Juan Ferlini, José Penelón y Agustín Muzzio, que se negaba a apoyar la ruptura de relaciones con Alemania y mantenía la posición "internacionalista" (Campione, 2005a: 20; Camarero, 2017: 146-147). Penelón en esa oportunidad planteó que el PS debía ser un "partido revolucionario" antes que el "partido de gobierno", en una dura réplica a Justo (Tarcus, 2007: 498; Camarero, 2017: 148). En esa coyuntura intrapartidaria se enfrentaron dos grupos diferenciados: por un lado, la elite del PS, integrada por sectores universitarios (médicos y abogados), que provenían en ciertos casos de familias de buena posición económica, y con experiencia parlamentaria; por otro lado, un sector juvenil, situado fuera del ámbito parlamentario y que carecía de formación universitaria (Campione, 2005b: 156). Quizá Buira, que tuvo escasas intervenciones en el Congreso, ${ }^{17}$ maduró en ese contexto las ideas sobre la dirigencia partidaria que a inicios de la década siguiente fueron nodales en su decisión de abandonar el PS e ingresar al Partido Comunista (PC).

Germinal al informar a sus lectores sobre el III Congreso Extraordinario se jactaba, al analizar el triunfo de la minoria, de que en el socialismo no había "caudillos" ni "jefes", así como también que para ellos la democracia era "algo más que una bella teoria, algo más que una abstracción generosa o una frase capaz de dar substancia al discurso y de señalar una aspiración colectiva". Para los redactores, incluso era "pueril" hablar "de desgarramientos y de renuncias", como hacian los opositores. El ejemplo que corroboraba sus planteos había tenido lugar el 1 de mayo, cuando "cogidos del brazo marchaban" dos referentes de las "tendencias antagónicas": de Tomaso y Ferlini. Así desmentían, según ellos, las opiniones de aquellos que "solo conciben la unanimidad y el incondicionalismo y hacen del culto a los hombres la base politica de una democracia". ${ }^{18}$ Sin duda, la interpretación que hacían era demasiado optimista, ya que las derivas del conflicto terminaron con una nueva escisión del PS y con la salida de varios militantes del socialismo santarroseño en los años posteriores. Pero aún para eso faltaba tiempo; ahora centremos la atención en el rol que tuvieron los agricultores so-

16. Partido Socialista, Versión taquigráfica del II Congreso Extraordinario (XIV Congreso Nacional), Buenos Aires, Talleres Gráficos de L.J. Rosso y Cía., 2015, pp. 160-161 y $173-175$.

17. Ver III Congreso Nacional Extraordinario del PS (1917: 12).

18. Germinal, 1 de mayo de $1917, \mathrm{n}^{\circ} 52$, Santa Rosa. 
cialistas en la organización del movimiento agrario durante la segunda mitad de las década del 10.

\section{La organización agraria: ¿un logro socialista?}

Como adelantamos, algunos agricultores socialistas tuvieron participación activa en el movimiento agrario antes de la constitución formal del PS. Luego del Grito de Alcorta, el 18 de agosto de 1912 Antonio Buira organizó la Liga Agraria en la colonia Inés y Carlota y al mes siguiente la entidad quedó constituida. Él fue su secretario general y lo secundó Eliseo Tarquini. Si bien durante la Gran Guerra la Liga estuvo prácticamente desarticulada, una vez reorganizada en 1918 Buira se desempeñó nuevamente como secretario general de la entidad y la presidencia recayó en Luis Denegri, un agricultor vinculado con el Centro Socialista de Santa Rosa. A decir verdad, dicha reorganización fue fruto del accionar en el ámbito rural de los agricultores socialistas, ya sea que formaran parte efectivamente o no del Centro capitalino. Antes veíamos que Buira en 1915 planteaba en el II Congreso Extraordinario que los socialistas pampeanos se dedicaban con ahínco "a la acción puramente gremial". Sin duda, se refería a las tareas realizadas para organizar a los colonos. Ese mismo año en Germinal podía leerse lo siguiente, luego de la realización de una asamblea en la colonia Espiga de Oro ante la pretensión del propietario de subir los arrendamientos: "La actitud de los colonos merece toda nuestra simpatía y hemos de acompañarlos desde aquí con el mayor entusiasmo. [...] Pero los colonos ya conocen el camino del éxito, y una vez más demostrarán lo que puede la unión y la conciencia de clase”. En la misma edición, señalaban que Buira fue convocado especialmente a la reunión "a fin de coordinar ideas tendientes a la iniciación de una agitación de resistencia contra dichos contratos" con el objeto de "obtener la rebaja del arriendo y la anulación de varias cláusulas que se conceptúan abusivas". ${ }^{19}$ Según planteó Buira en dicha asamblea, lo que debían hacer los agricultores era favorecer la organización agraria, con lo cual no solo podrian luchar por la rebaja de los arriendos sino además lograr el acceso a la propiedad de la tierra. ${ }^{20}$

En 1916 se celebró el cuarto aniversario de la fundación de la Liga Agraria con un festejo que duró tres dias y reunió alrededor de mil personas. En esa oportunidad los principales oradores fueron los hermanos Buira, Florentino Ghiribaldi y Antonio Torres, todos ellos antiguos integrantes de la entidad. En la misma oportunidad que reseñaron el evento, en Germinal informaban que se realizarian reuniones de colonos

19. Germinal, $\mathrm{n}^{\circ} 14,27$ de septiembre de 1915, Santa Rosa.

20. Germinal, $\mathrm{n}^{\circ} 15,4$ de octubre de 1915, Santa Rosa. 
en Mauricio Mayer, Colonia Barón, Metileo y Winifreda, donde harian uso de la palabra los Buira y Ghiribaldi. ${ }^{21}$ La necesidad de reorganizar la Liga fue una cuestión que ocupó las páginas de Germinal al menos desde 1915, motivo por el cual las proclamas y notas de Antonio Buira tuvieron alli un lugar central. Entre sus impulsores, advertian, "predomina el propósito de someter a cada adherente a una severa fiscalización", ya que la historia demostraba "el profundo egoísmo de muchos elementos que ingresaron anteriormente sin el espiritu de sacrificio y solidaridad necesarios a una asociación de resistencia". ${ }^{22}$ Incluso Buira solía referirse al respecto en las reuniones agrarias, como cuando afirmó en Winifreda que los colonos debían comprender la importancia de "conservar su gremio". ${ }^{23}$

El secretario general interpelaba a los agricultores y, a través de manifiestos de la Liga Agraria, planteaba que ante "la voracidad creciente de toda clase de especuladores" era necesario "aunar voluntades a fin de contrarrestar la acción nefasta" de los explotadores. Por tal motivo, la Liga era "el mejor estímulo para renovar hoy la agitación agraria de ayer". ${ }^{24}$ Eliseo Tarquini, por su parte, afirmaba que para obtener sus reivindicaciones tenian que unirse y trabajar con "inteligencia". La manera más fácil de hacerlo era "engrosar las filas de la Liga Agraria", ya que era el "órgano genuino de los agricultores de la Pampa". ${ }^{25}$

Para los líderes agrarios la organización tenía que ser permanente y no acotarse a los momentos criticos, es decir, a partir del movimiento "inteligente" había que superar la desunión de los colonos. Para eso, debían "conservar su gremio", como les planteó Buira a los colonos de la zona de Winifreda en una reunión, luego de la cual se creó una Comisión provisoria y las colonias designaron delegados. El vicepresidente de dicha Comisión fue Rafael Durán, agricultor que era agente de Germinal en Winifreda, Mauricio Mayer y Colonia Barón. ${ }^{26}$

Desde fines de 1917, Germinal acentuó más la difusión de las actividades organizadas por la Liga. En las asambleas los oradores eran Ghiribaldi, Tarquini, Carnicelli, Nievas, Ottone y Antonio Buira. ${ }^{27}$ En diciembre de 1917 se llevó a cabo en Santa Rosa un Congreso Agrícola y

21. Germinal, $\mathrm{n}^{\circ} 38,1$ de septiembre de 1916, Santa Rosa.

22. Germinal, $\mathrm{n}^{\circ} 27,14$ de marzo de 1916, Santa Rosa.

23. Germinal, $\mathrm{n}^{\circ}$ 51, 15 de abril de 1917, Santa Rosa.

24. Germinal, $\mathrm{n}^{\circ}$ 33, 2 de junio de 1916, Santa Rosa.

25. Germinal, $\mathrm{n}^{\circ}$ 69, 22 de noviembre de 1917, Santa Rosa.

26. Germinal, $\mathrm{n}^{\circ} 51,15$ de abril de 1917, Santa Rosa.

27. Germinal, $\mathrm{n}^{\circ} 64,18$ de octubre de 1917, y n 66, 1 de noviembre de 1917, Santa Rosa. 
el enviado especial de La Vanguardia relataba que al arribar a la capital pampeana lo esperaban "viejos camaradas, antiguos agricultores, [...] [líderes] de los primeros y grandes movimientos agrarios que conmovieron las zonas agrícolas de la república". Era "gente humilde, ruda, espontánea, sincera, inteligente" y entre ellos estaban seguramente los agricultores mencionados. ${ }^{28}$ Por cierto, Antonio Buira fue uno de los secretarios del Congreso. ${ }^{29}$ Nicolás Repetto también asistió y, junto con Denegri, refutó los planteos de algunos integrantes de la burocracia estatal que desestimaban la importancia que tenía el latifundio como problemática nacional. El médico socialista rebatió ese planteo en una conferencia realizada en el Teatro Español de Santa Rosa ante un público de colonos, donde afirmó que las problemáticas reales del agro radicaban en la breve duración de los contratos de arrendamiento, en la falta de indemnización por las mejoras introducidas, en las extorsiones a los agricultores y en la existencia de latifundios. ${ }^{30}$

Los colonos que participaron en dicho Congreso pudieron, además de escuchar a Repetto, acceder al folleto La cuestión agraria, publicado por Justo (1917), ya que el autor había enviado ejemplares para distribuir entre los congresales. El referente más importante del PS era además autor de proyectos legislativos de orden agrario, motivo por el cual en La Vanguardia señalaban que "el congreso agrícola de La Pampa ha comprendido la necesidad y la urgencia de que esos proyectos sean ley", ${ }^{31}$ a la vez que Buira afirmaba en una nota posterior que el Congreso se había orientado "por el lado de las ideas más avanzadas que el Partido Socialista ha traído al debate público". ${ }^{32}$ Es muy probable que Buira consultara La cuestión agraria antes de escribir dicha nota, ya que allí retomó los tópicos abordados por Justo, entre ellos, el impuesto progresivo sobre la renta del suelo (Justo, 1917: 34-53). Como puede advertirse, esos agricultores conocían las propuestas del PS para el agro y tenían acceso a los dirigentes partidarios encumbrados. Sin embargo, los líderes agraristas no titubearon a la hora de plantearles críticas a los referentes socialistas, como se observará en el caso de Antonio Buira.

El secretario general de la Liga a comienzos de 1918 planteaba que "un fuego de santa rebeldía va encendiéndose en el corazón de nuestros campesinos", ya que "en el surco y desde el arado interrogaban a la naturaleza sobre su derecho a la posesión definitiva del suelo que

28. La Vanguardia, $\mathrm{n}^{\circ} 3756,14$ de diciembre de 1917, Buenos Aires.

29. La Vanguardia, $\mathrm{n}^{\circ} 3753,11$ de diciembre de 1917, Buenos Aires.

30. Germinal, $\mathrm{n}^{\circ}$ 72, 13 de diciembre de 1917, Santa Rosa.

31. La Vanguardia, $\mathrm{n}^{\circ} 3754,12$ de diciembre de 1917, Buenos Aires.

32. Germinal, $\mathrm{n}^{\circ} 75,3$ de enero de 1918, Santa Rosa. 
cultivaban". Por ello, la "gran obra generosa y redentora" de la Liga Agraria consistía en "libertar a los parias del campo del yugo ignominioso de la esclavitud a que los han sometido los señores feudales". Según Buira, la entidad sería "la heroína de los grandes acontecimientos que han de moldear el espíritu nuevo sobre la propiedad de la tierra". ${ }^{33}$ Por su parte, Carnicelli señalaba: "Porque nuestros seculares enemigos marchan unidos, y nosotros desunidos, desunión que es producida por ellos mismos para explotarnos a su antojo. [...] Tengo confianza que el pueblo despertará de su largo sueño, y al hacerlo unidos todos venceremos a nuestros enemigos, traduciendo en realidad la inmortal frase de ¡Libertad, Igualdad y Fraternidad...!”. ${ }^{34}$ Pero no solo los agricultores insistian al respecto. Otro integrante del Centro, que firmaba con el seudónimo Ulises, planteaba la "necesidad de la organización gremial de los colonos". 35

El 15 de septiembre de 1918 la Liga programó una reunión en Santa Rosa con el objetivo de buscar una solución a los problemas de los agricultores ante el aumento de los arrendamientos, las bolsas y los implementos agrícolas, en un contexto signado a su vez por el bajo precio del cereal. A ella asistieron 120 agricultores, fue presidida por Ottone y entre los oradores se destacaron Buira, Tarquini y Blanco ${ }^{36} \mathrm{En}$ los meses siguientes se realizaron reuniones en diferentes localidades y colonias del Territorio y, cuando en marzo de 1919 la Federación Agraria Argentina (FAA) convocó a la huelga, la Liga Agraria decretó lo propio bajo la consigna "iNo arar, no sembrar!". Para ese entonces, Denegri y Buira estaban secundados por Glerean, Ghiribaldi, Torres, Blanco, Carnicelli, Tarquini, Ottone, Nievas y José Azzi. El pliego de condiciones que confeccionó la Liga Agraria para enviar al Congreso nacional era más radical que el de la FAA y retomaba iniciativas del PS para resolver los problemas agrarios. ${ }^{37}$ Buira entonces escribía en La Vanguardia que continuaban "con encomiable actividad los trabajos [...] en pro de la agitación iniciada" y que la lucha sería "áspera". ${ }^{38}$

Los acontecimientos motivaron la visita en abril del ministro de Agricultura Alfredo Demarchi, que prometió estudiar la problemática de los huelguistas para resolver la situación. Mientras tanto, la Liga convocó a los delegados de las seccionales a una convención en Santa

33. Germinal, $\mathrm{n}^{\circ} 78,24$ de enero de 1918, Santa Rosa.

34. Germinal, $\mathrm{n}^{\circ}$ 96, 6 de junio de 1918, Santa Rosa.

35. Germinal, $\mathrm{n}^{\circ} 102,18$ de julio de 1918, Santa Rosa.

36. Germinal, $\mathrm{n}^{\circ} 111,19$ de septiembre de 1918, Santa Rosa.

37. En cuanto a los puntos del pliego, ver Asquini (1999).

38. La Vanguardia, $\mathrm{n}^{\circ} 4212,18$ de marzo de 1919, Buenos Aires. 
Rosa para discutir cómo continuar: alli se resolvió no retornar al trabajo si no se atendian todos los puntos de carácter legislativo del pliego. La respuesta que dio el gobierno nacional fue la represión mediante la aplicación de la Ley de Defensa Social. Eso incluyó el envío de la gendarmería fronteriza, la prohibición de reuniones públicas y además la persecución y encarcelamiento de los líderes. Especial encono tuvieron con Antonio Buira algunos agricultores y la policia, a quien se referian como el "agitador conocido", difusor de lo que concebían como "teorías anárquicas" y referente indiscutido de la Liga que, como otros, se plegaba al "modus vivendi" de la entidad con el fin de obtener "sus recursos de vida" a partir del dinero que recaudaban entre los colonos, discurso que tendía a desacreditar el accionar de los huelguistas. ${ }^{39}$

Los sucesos, replicados en las provincias de Córdoba, Santa Fe y Buenos Aires, adquirieron trascendencia nacional. Repetto abordó el tema en la Cámara de Diputados para interpelar al ministro del Interior. En relación con lo ocurrido en el Territorio, el médico socialista señalaba que el comisario de Trenel recorría las chacras para intimidar a los agricultores y que en Winifreda una reunión pacífica de colonos había sido disuelta a tiros (Repetto, 1919: 4-5). En efecto, según declaró un testigo, Glerean planteaba lo siguiente cuando irrumpió la policía: "Hermanos nosotros hemos tenido una reunión de cien delegados en Santa Rosa en la cual nada hemos podido conseguir y estamos resueltos de seguir con la huelga hasta que salgamos triunfantes". ${ }^{40}$ En ese contexto, en Germinal se preguntaban: "¿Qué esperan el gobierno y el congreso nacional para resolver este grande y grave problema? ¿Acaso alguna Jacquerie de los campesinos argentinos?". ${ }^{41}$ Al promediar junio de 1919 la huelga había concluido, aunque la represión se prolongó hasta julio. Los líderes más importantes fueron detenidos, entre ellos Denegri, Buira y Glerean. A fines de mayo de 1919 los dos últimos fueron liberados, pero otros siguieron entre rejas hasta 1921.

\section{Conflictos en el PS: salida de los terceristas y repliegue de la organización agraria}

A un año de iniciada la huelga agraria, Antonio Buira y Glerean se presentaron como candidatos por el socialismo en las elecciones municipales de Santa Rosa, junto con Pico y Nale. Ahora bien, ¿cómo explicar la posterior salida del principal dirigente agrario de las filas partidarias?

39. Expediente 294, Juzgado Letrado de la Gobernación de La Pampa, Infracción a la ley 7.029, implicados Luis Glerean y Antonio Buira, Santa Rosa, 1919, foja 5. 40. Ídem, foja 54.

41. Germinal, 3 de abril de 1919, $n^{\circ}$ 139, Santa Rosa. 
Ciertos indicios aparecian en sus intervenciones en los Congresos, pero a comienzos de la década del 20 sus críticas se profundizaron. Centremos la atención en el debate que se suscitó en Germinal durante los meses previos al IV Congreso Extraordinario del PS.

Entre principios de agosto y fines de diciembre de 1920 tuvo lugar allí una intensa polémica, cuyos protagonistas fueron Demetrio Buira y Ulises (que integraba la Comisión Administrativa del Centro). El primero publicó una nota titulada "Cosas de casa", donde reflexionaba sobre los debates suscitados en La Vanguardia por el envío de un delegado del PS a Rusia para estudiar "seria y objetivamente" lo que allí ocurría. Además, en el texto desacreditaba las opiniones vertidas por De Tomaso sobre el tema. ${ }^{42}$ En el número siguiente Ulises bajo el mismo título afirmó que el envio de una delegación a Rusia ejerceria "el efecto de una ducha de agua fría sobre los acalorados cerebros de los afiliados". Según él, la adhesión a la III Internacional no resolvería los problemas de la política criolla, la carestía de la vida ni el atraso político, económico y gremial de los trabajadores argentinos. ${ }^{43}$ Buira volvió a la carga y señaló que habia que tomar una resolución: se estaba con los socialdemócratas o se estaba con los trabajadores, opción esta última más acertada porque, según su expresión, "ya desgraciadamente estamos bastantes (sic) desmerecidos en el seno de los obreros". ${ }^{44}$ Ulises afirmó luego que Buira estaba "contaminado con el microbio de la fácil y aparatosa demagogia maximalista". ${ }^{45}$ En las notas posteriores Buira criticó a su rival por esconderse detrás de un seudónimo y extendió sus diatribas a De Tomaso, Mario Bravo, Federico Pinedo y Héctor González Iramain, mientas que Ulises señaló que era contradictorio que un socialista de primera fila fuera un "revolucionario" que soñaba "con las bayonetas de Trosky (sic) para implantar la nueva sociedad". ${ }^{46}$

En esa coyuntura, el afiliado Ignacio Noreña publicó una nota en la que planteaba que era "vergonzoso" que los socialistas censuraran a la "nueva Rusia" y llamaran "ilusos y líricos" a los que integraban la "extrema" izquierda partidaria. Este afiliado, que no era agricultor, concluía diciendo que había que seguir "la ruta trazada por Marx y Engels al proletariado", ${ }^{47}$ a la vez que Buira en otra nota refutaba a Ulises y

42. Germinal, $\mathrm{n}^{\circ} 208,5$ de agosto de 1920, Santa Rosa.

43. Germinal, $\mathrm{n}^{\circ} 209,12$ de agosto de 1920, Santa Rosa.

44. Germinal, $\mathrm{n}^{\circ} 211,26$ de agosto de 1920, Santa Rosa.

45. Germinal, $\mathrm{n}^{\circ}$ 215, 23 de septiembre de 1920, Santa Rosa.

46. Germinal, $\mathrm{n}^{\circ} 216,30$ de septiembre de 1920, y $\mathrm{n}^{\circ} 217,7$ de octubre de 1920, Santa Rosa.

47. Germinal, $\mathrm{n}^{\circ}$ 217, 7 de octubre de 1920, Santa Rosa. 
para argumentar citaba el Manifiesto Comunista. Demetrio era duro en sus observaciones: para él, el PS debía "evolucionar doctrinariamente" y había que sanear las filas partidarias del "bandidaje universitario" que se incorporó en busca de una "sociedad de socorros mutuos". ${ }^{48}$ Estas ideas sobre la vuelta a Marx también se advierten en las palabras de Antonio Buira en la asamblea que se realizó en diciembre de 1920 en el Centro santarroseño, ocasión en la que se elegiría un delegado para el Congreso de Bahía Blanca y un mandato respecto de la adhesión o no a la III Internacional. En Germinal reseñaron su intervención, donde cuestionó el "cadáver" de la II Internacional, la "tendencia electoral" del PS y su "aislamiento del seno de los sindicatos", a la vez que reclamó el retorno a "los dictados del marxismo y el engelsismo". Para Buira, el PS debía alinearse con Moscú, ya que los rusos llevaban "el estandarte del Socialismo". ${ }^{49}$

Esa opinión fue la que se impuso en la votación y Antonio fue electo delegado para el futuro Congreso. Luego de ello, Ulises criticó una vez más la postura "tercerista" del Centro afirmando que había triunfado el "verbalismo", término despectivo con que se aludía al sector izquierdista del PS que disentía con la postura partidaria oficial sobre la Revolución rusa. ${ }^{50}$ Además, puso en cuestión la capacidad del Centro de Santa Rosa en materia cultural, cooperativa y gremial. Por ello, concluía Ulises, intentaba "lavar los pecados de su propia incapacidad, sumergiéndose en el Jordán de la tercera [III Internacional] y votando su sumisión incondicional a los santos íconos del nuevo dogma revolucionario de Moscú". ${ }^{51}$ En respuesta, Antonio Buira publicó otra nota titulada "Nuestra adhesión a Moscú (A Ulises cordialmente)". Entre otras cosas, allí planteó que era "lamentable" que menospreciara el "brioso movimiento agrario", iniciado por integrantes del Centro en 1919, "que se extendió por todo el país y cuya repercusión fue tan grande que hizo aparecer una nueva y abundante literatura destinada a resolver nuestro pavoroso problema agrario". Ulises estaba en su derecho, según Buira, de disentir con ellos en "la vuelta a la vieja y honrada senda del socialismo marxista", pero no podía aplicarle por ello "dicterios un poco insolentes y demasiado vulgares". ${ }^{52}$

Era evidente que el líder agrario concebía a la organización de los

48. Germinal, $\mathrm{n}^{\circ}$ 219, 21 de octubre de 1920, Santa Rosa.

49. Germinal, $\mathrm{n}^{\circ}$ 228, 23 de diciembre de 1920, Santa Rosa.

50. El término era utilizado también en el seno de otras fuerzas de izquierda, por ejemplo en el Partido Socialista Internacional (PSI). Al respecto, ver Camarero (2017: 186-187).

51. Germinal, $\mathrm{n}^{\circ} 228,23$ de diciembre de 1920, Santa Rosa.

52. Germinal, $\mathrm{n}^{\circ}$ 229, 30 de diciembre de 1920, Santa Rosa. 
colonos como un logro del PS, pero también que un núcleo importante de socialistas estaba en desacuerdo con el desinterés partidario por la actividad gremial. Ello explica quizás la salida de un número considerable de socialistas en esos años: en 1918 el PS pampeano tenía 96 afiliados y en 1921 esa cifra descendió a 68 (Anuario Socialista, 1930: 70). La pérdida de afiliados está vinculada con la crisis interna del PS, situación que sin duda se potenció a raíz del debate desarrollado en Germinal. Si bien faltan estudios al respecto, con seguridad la retracción de la membresía partidaria incidió en otros Centros Socialistas y no solo en el de la capital, donde los "agrarios" tenían mucha injerencia.

Entre los que abandonaron el Centro santarroseño se destacaban los hermanos Buira y Noreña. El principal líder agrario le escribió luego a Nicolás Repetto y en una carta le decía que se habian pasado muchos socialistas al PC porque ya no podían coexistir con "fifis" que le daban al PS un tono "amarillo". ${ }^{53}$ Según le decía Antonio al referente partidario, el PS se había convertido en una vía "de fácil encumbramiento político", hecho que explicaba la aparición de "tanto maula" entre los socialistas. Uno de los blancos de su crítica era el abogado De Tomaso, a quien catalogaba de "pillo redomado". ${ }^{54} \mathrm{El}$ encono era motivado porque desde fines de 1920 dicho integrante del Comité Ejecutivo impulsó la expulsión de los "terceristas", la disolución de los Centros Socialistas que adherian a esas ideas y defendió la posición antitercerista en el Congreso de Bahía Blanca (Tarcus, 2007: 172). Por su parte, Demetrio Buira le planteó a Repetto la necesidad de "hacerle rectificar los conceptos que han vertido sobre la Revolución Rusa algunos diputados como 'Pinedito' y De Tomasso (sic)", ${ }^{55}$ a quienes Demetrio incluia entre el "bandidaje universitario" que se posicionó favorablemente en las filas partidarias, tal como afirmaba en su debate con Ulises.

Fue en esa coyuntura en la que Antonio Buira rechazó una propuesta de Justo para ser candidato a diputado por el PS en Buenos Aires. Según le confesó a Repetto, tuvo miedo cuando el PS comenzó a crecer "de golpe" y a llenarse de personas con "malas intensiones", por eso decidió irse al PC y continuar en el campo, con la organización de los trabajadores. ${ }^{56}$ Sin embargo, luego de la cruda represión estatal la Liga

53. Los integrantes del PC asociaban el color amarillo con ciertas organizaciones a las que catalogaban de "burocráticas" y "reformistas" (Camarero, 2007: 91 y 104).

54. Carta de Antonio Buira a Nicolás Repetto, 5 de diciembre de 1921, Fondo Repetto, Cedinci.

55. Carta de Demetrio Buira a Nicolás Repetto, 1 de mayo de 1922, Fondo Repetto, Cedinci.

56. Carta de Antonio Buira a Nicolás Repetto, 5 de diciembre de 1921, Fondo Repetto, Cedinci. 
no recuperó su ascendiente en el movimiento agrario, hecho en el que sin duda incidió también el conflicto interno en el seno del PS pampeano. En ese marco, la FAA, entidad cuestionada por los hermanos Buira debido a su orientación ideológica, absorbió algunas seccionales de la Liga. Ante esa situación, Demetrio Buira le reconocía a Repetto en un tono pesimista que "esa media docena de encumbrados en la dirección de la FAA [...] para desgracia de la organización agraria argentina mantienen y mantendrán esos puestos" ${ }^{57}$ Este último retornaria años después al PS y llegaria a ser diputado nacional por Buenos Aires, pero Antonio Buira nunca volvió a las filas socialistas, si bien continuó apoyando la organización de los colonos y los trabajadores en general.

\section{Reflexiones finales}

Entre 1913 y 1921, el PS pampeano tenía en sus filas un número importante de agricultores, situación que no es extraña si tenemos en cuenta las características de la región en términos productivos. Algunos de ellos integraban el Centro Socialista de Santa Rosa, otros eran agentes de Germinal, en tanto que la mayoría se incorporó a la Liga Agraria: su Comisión estaba conformada casi en su totalidad por socialistas. La propaganda liguista y los integrantes de la entidad llegaban a los puntos más apartados del agro, motivo por el cual podría suponerse que la palabra socialista circuló en las zonas rurales, al menos en la etapa analizada, más de lo que la historiografia había comprobado hasta ahora. El principal objetivo de los miembros de la Liga era la organización gremial de los agricultores, y la huelga agraria de 1919 dejó en evidencia que no escatimaron esfuerzos en ese sentido, al punto que fue necesaria la represión estatal para acabar con la medida de fuerza. Más aún, pese a las escasas concesiones obtenidas, el PS se arrogaba la movilización de los agricultores cuando pasaba revista de su desempeño en el plano gremial.

El único que se atrevió a desmerecer el rol de los agricultores en ese sentido fue Ulises, y lo hizo al calor del debate suscitado en el seno del Centro capitalino entre terceristas y antiterceristas. Pero hacía ya tiempo que existían voces críticas en el socialismo pampeano sobre la postura justista respecto de la cuestión gremial. No es casual que el secretario general de la Liga Agraria, uno de los exponentes de esa línea crítica, considerara "lamentable" el planteo de Ulises, entre otras cosas porque olvidaba el "brioso movimiento agrario" que ellos gestaron. La ruptura partidaria ocurrida luego del debate en Germinal y del IV Con-

57. Carta de Demetrio Buira a Nicolás Repetto, 5 de marzo de 1923, Fondo Repetto, Cedinci. 
greso Extraordinario implicó la pérdida de casi el treinta por ciento de los afiliados al socialismo, según la evidencia recabada. Esa situación al mismo tiempo incidió en el declive de la organización agraria y la consecuente pérdida de posiciones por parte de la Liga. No sabemos con exactitud cuantos agricultores se alejaron del PS y de la entidad gremial de manera definitiva. No obstante, los datos son elocuentes: en la década del 20 algunas de las seccionales de la Liga que estaban dispersas iniciaron su progresivo acercamiento a la FAA, entidad que acabó absorbiéndolas.

Los conflictos intrapartidarios suscitados a raíz de la cuestión gremial, sumados a la crisis que generó en las izquierdas el proceso revolucionario en Rusia, jaquearon la aquiescencia alcanzada por los agricultores del PS en el ámbito rural. Aunque efimero, no pierde por ello relevancia el rol movilizador de un grupo de agricultores que intentó difundir la palabra socialista en el agro, apostó a la organización de los colonos y rebatió desde la praxis las ideas que defendía la elite partidaria. ¿Es posible pasar por alto el rol gravitante de estos sujetos sociales en el despliegue del socialismo en el agro? ¿No es un obstáculo para el análisis histórico desatender la composición de clase del PS y trazar un parangón entre la dirigencia plebeya del Territorio y los sectores universitarios que tenian el predominio en el ámbito legislativo? Al prestar atención a las diferencias que los propios arrendatarios establecían con sus camaradas y revisar su accionar en el plano gremial, es sencillo responder los interrogantes. El objetivo de estas páginas queda resuelto: la historiografia tiene más elementos ahora para explicar el auge y la crisis del movimiento agrario socialista durante la segunda década del siglo XX.

\section{Bibliografia}

Adelman, Jeremy (1989), "Una cosecha esquiva. Los socialistas y el campo antes de la primera guerra mundial", Anuario IEHS, $\mathrm{n}^{\circ}$ 4, UNCPBA, Tandil, pp. 293-333.

Armani, Roberto (2006), Trenel. 100 años de historia, Trenel: Municipalidad de Trenel.

Asquini, Norberto (1999), "La gran huelga agraria del '19", en Norberto Asquini, Walter Cazenave y Jorge Etchenique, Conflictos sociales en La Pampa (1910-1921), Santa Rosa: Fondo Editorial Pampeano, pp. 85-94.

Barandiarán, Luciano (2010), "La propaganda socialista en el campo bonaerense: la experiencia de los "comités de zona" (1930-1943)", Nuevo Topo. Revista de Historia y Pensamiento Crítico, $\mathrm{n}^{\circ} 7$, septiembre-octubre, Buenos Aires, pp. 147-166.

Belkin, Alejandro (2013), "La critica del sindicalismo revolucionario argentino 
al parlamentarismo (1905-1912)", Archivos de Historia del Movimiento Obrero y la Izquierda, año II, n ${ }^{\circ}$, septiembre, Buenos Aires, pp. 81-106. Camarero, Hernán (2005), "Socialismo y movimiento sindical: una articulación débil. La COA y sus relaciones con el PS durante la década de 1920", en Hernán Camarero y Carlos Miguel Herrera (eds.), El Partido Socialista en Argentina. Sociedad, politica e ideas a través de un siglo, Buenos Aires: Prometeo, pp. 185-217.

- (2007), A la conquista de la clase obrera. Los comunistas y el mundo del trabajo en la Argentina, 1920-1935, Buenos Aires: Siglo XXI.

- (2015), "El Partido Socialista de la Argentina y sus espinosas relaciones con el movimiento obrero: un análisis del surgimiento y disolución del Comité de Propaganda Gremial, 1914-1917”, Izquierdas, n²2, enero, pp. 158-179.

- (2017), Tiempos rojos. El impacto de la Revolución Rusa en la Argentina, Buenos Aires: Sudamericana.

Camarero, Hernán y Schneider, Alejandro (1991), La polémica Penelón-Marotta (marxismo y sindicalismo soreliano), 1912-1918), Buenos Aires: CEAL.

Campione, Daniel (2005a), El comunismo en Argentina. Sus primeros pasos, Buenos Aires: Ediciones del CCC.

- (2005b), “¿Partido revolucionario o partido de gobierno? La fundación del Partido Socialista Internacional”, en Hernán Camarero y Carlos Miguel Herrera (eds.), El Partido Socialista en Argentina. Sociedad, politica e ideas a través de un siglo, Buenos Aires: Prometeo, pp. 145-157.

Censo General del Territorio Nacional de la Pampa (1942), tomo I: Población, Gobernación de La Pampa: Ministerio del Interior, República Argentina.

Ceruso, Diego (2015), La izquierda en la fábrica. La militancia obrera industrial en el lugar de trabajo, 1916-1943, Buenos Aires: Imago Mundi.

- (2017), "El Partido Socialista y la cuestión gremial. Debates internos durante la primera mitad de la década infame", Archivos de Historia del Movimiento Obrero y la Izquierda, año V, $\mathrm{n}^{\circ} 10$, marzo, Buenos Aires, pp. 119-139.

Di Liscia, María Silvia y Andrea Lluch (2014), "La población pampeana y sus transformaciones", en Andrea Lluch y Claudia Salomón Tarquini (eds.), Historia de La Pampa. Sociedad, politica, economía. Desde los poblamientos iniciales hasta la provincialización (ca. 8.000 AP a 1952), Santa Rosa: EdUNLPam, pp. 101-113.

Doeswijk, Andreas (2014), Los anarco-bolcheviques rioplatenses (1917-1930), Buenos Aires: Cedinci.

Folco, Gonzalo (2014), “¡Están dando la biaba! El conflicto obrero rural en el Territorio Nacional de La Pampa 1914-1921", Razón y Revolución, $\mathrm{n}^{\circ}$ 27, Buenos Aires, pp. 115-141.

Graciano, Osvaldo (2006), "El agro pampeano en los "clásicos" del socialismo argentino. Las propuestas hacia el campo de Juan B. Justo, 18941928”, en Osvaldo Graciano y Talía Gutiérrez (dir.), El agro en cuestión. 
Discursos, politicas y corporaciones en la Argentina, 1870-2000, Buenos Aires: Prometeo, pp. 87-115.

Herrera, Carlos Miguel (2007), Las huellas del futuro. Breve historia del Partido Socialista de Argentina, Buenos Aires: Editora La Vanguardia. Justo, Juan B. (1917), La cuestión agraria, Buenos Aires: La Vanguardia. Martínez Mazzola, Ricardo (2011), "La neutralidad como problema y como solución. La política gremial del Partido Socialista después de la ruptura sindicalista", Identidades, año $1, \mathrm{n}^{\circ} 1$, diciembre, pp. 1-20.

Martocci, Federico (2015), La politica cultural del Partido Socialista en el Territorio Nacional de la Pampa: dispositivos y prácticas de intervención de sus dirigentes e intelectuales (1913-1939), Santa Rosa: EdUNLPam.

Poy, Lucas (2016), "'Esparcidos en el inmenso territorio de la república'. Los primeros pasos del Partido Socialista en las provincias (1894-1902)", Población \& Sociedad, vol. 23, n 2, Buenos Aires, pp. 149-177.

Repetto, Nicolás (1919), La huelga agraria, Buenos Aires: Lotito \& Barberis. Tarcus, Horacio (dir.) (2007), Diccionario biográfico de la izquierda argentina. De los anarquistas a la "nueva Izquierda" (1870-1976), Buenos Aires: Emecé.

Tortti, María C. (1989), Estrategia del Partido Socialista. Reformismo politico y reformismo sindical. Buenos Aires: CEAL.

Valencia, Luciano (2008a), La transformación interrumpida. El Partido Socialista en el Territorio Nacional de La Pampa (1913-1938), Santa Rosa: Fondo Editorial Pampeano.

- (2008b), "Luchas agrarias en el campo pampeano", en AA.VV., En la remota orilla del recuerdo. Eduardo Castex, 1908-2008, Municipalidad de Eduardo Castex-Banco de la Nación, pp. 156-164.

III Congreso Nacional Extraordinario del PS. Versión taquigráfica de los discursos (1917), Partido Socialista, en La Vanguardia, 26 y 27 de mayo, Buenos Aires.

$$
* * *
$$

Título: Rise and crisis of the Pampean Socialist Party and its role in the organization of the agrarian movement (1913-1921)

Resumen: El artículo explora el rol del Partido Socialista (PS) en la organización del movimiento agrario en un espacio del interior argentino que tenía una población rural y una economía basada en la actividad primaria. El recorte temporal se inicia con la creación del PS en el Territorio Nacional de La Pampa y concluye con la desarticulación de la Liga Agraria por la represión estatal y la salida de agricultores "terceristas" del PS. Procuramos brindar algunos elementos para explicar la expansión del socialismo en una zona rural, donde los líderes de la Liga Agraria, que adherian a esa fuerza politica, veian en ella un logro resonante y no acataban la postura de la dirigencia nacional de manera acrítica. En cambio, analizaban con autonomía la realidad del PS y se basaban en sus experiencias para discutir temas delicados, entre ellos el vínculo con la esfera gremial. 
Palabras clave: Partido Socialista - agricultores - Liga Agraria - Territorio Nacional de La Pampa

Abstract: The article explores the role of Socialist Party (SP) in the organization of the agrarian movement within rural towns with rural population and a primary based economy. The time framework is located within the creation of the SP in National Territory of La Pampa and finishes with the dislocation of the Agrarian League because of state repression and the departure of "tertiary" farmers of the SP. We try to offer some elements to explain the expansion of socialism within a rural area, where leaders of the Agrarian League, who were in favor of this politics, consider it a great achievement and did not attack the national leadership point of view acritically. On the other hand, they analyzed with autonomy the reality of the SP and based their experiences to discuss fine issues, among them the relationship with unions.

Key words: Socialist Party - farmers - Agrarian League - National Territory of La Pampa

Recepción: 6 de abril de 2017. Aprobación: 17 de noviembre de 2017. 